\title{
DUAS FACES DE UMA MESMA MOEDA? A ABORDAGEM DE TRUMP PARA $O$ TRIBUNAL PENAL INTERNACIONAL ${ }^{1}$
}

\author{
Marrielle Maia ${ }^{\mathrm{a}}$ \\ aé professora do Programa de Pós-Graduação em Relações Internacionais do Instituto de Economia e \\ Relações Internacionais da Universidade Federal de Uberlândia (PPGRI-IERI UFU). \\ Uberlândia, MG, Brasil. E-mail: marriellemaf@gmail.com \\ Orcid: 0000-0001-6857-6688 \\ Taynara Dias ${ }^{b}$
}

bé mestranda no Programa de Pós-Graduação em Relações Internacionais do Instituto de Economia e

Relações Internacionais da Universidade Federal de Uberlândia (PPGRI-IERI UFU).

Uberlândia, MG, Brasil.E-mail: taysdias@terra.com.br

Orcid: 0000-0001-6101-2345

http://dx.doi.org/10.1590/0102-045063/108

\section{Introdução}

Este artigo analisa a grande estratégia dos Estados Unidos para os instrumentos de justiça penal internacional, com ênfase na política para o Tribunal Penal Internacional (TPI) no governo Donald Trump. Para tanto, é relevante esclarecer que adotamos o conceito ampliado de grande estratégia como processo pelo qual o Estado articula os fins e os meios na perseguição do interesse nacional (Layne, 1998, p. 1).

Segundo Dorff (2001), a grande estratégia dos Estados Unidos é materializada nos Relatórios de Estratégia de

${ }^{1}$ A pesquisa tem apoio do CNPq e da Fapemig. 
Segurança Nacional (em sua sigla em inglês, NSS) que, de acordo com a legislação doméstica, devem ser apresentados anualmente pelas administrações dos Estados Unidos para o Congresso Nacional e ao público em geral. O processo de criação do documento envolve a interação entre os diferentes departamentos e agências do governo, ${ }^{2}$ o que promove um consenso interno sobre o desenho da grande estratégia que tem foco na interação entre os dois elementos do núcleo duro do interesse nacional: a segurança (variável da integridade física do Estado) e os valores americanos (dentre os quais a justiça, a democracia e os direitos humanos) (Dorff, 2001; Snider e Nagl, 2001).

Em estudos anteriores (Maia, 2012; 2014; Maia e Lemos, 2017) sobre a relação dos Estados Unidos com o TPI nos governos Bill Clinton, George W. Bush e Barack Obama, tendo os NSS como guias na construção de uma narrativa sobre a política dos Estados Unidos para o TPI, observou-se uma estratégia mais geral de promoção da justiça internacional (como um valor) atrelada à expansão das democracias como forma de alcançar segurança global, por meio da aceitação e até do apoio à criação e ao funcionamento de tribunais penais internacionais, desde que sua jurisdição não alcançasse os cidadãos norte-americanos. ${ }^{3}$

No que se refere ao TPI, a política ganhou contornos distintos nas administrações democratas e republicanas. Esses contornos são interpretados não como parte de uma nova estratégia no alcance dos interesses norte-americanos,

\footnotetext{
2 O documento é construído por meio da interação entre os diversos setores da administração. A minuta resultante desse processo é encaminhada ao Conselho de Segurança Nacional, que é o responsável pela aprovação do documento final. O Conselho é formado pelo vice-presidente, Secretário de Estado, Secretário de Defesa, Diretor da CIA (Central Intelligence Agency) e pelo Conselheiro de Segurança Nacional.

3 Para a conclusão foram estudados todos os Relatórios de Segurança Nacional (National Security Strategy-NSS) publicados durante as gestões Clinton (7 relatórios), W Bush (2 relatórios) e Obama (2 relatórios). (THE WHITE HOUSE, 1995, 1996, 1997, 1998, 1999, 2000, 2002, 2006, 2010, 2017a, 2017b)
} 
mas como diferentes táticas que envolveram a instrumentalização desse tipo de mecanismo internacional.

Nesse quadro, este ensaio busca compreender a abordagem de Trump para o TPI, em uma análise que considera a grande estratégia dos Estados Unidos para os instrumentos de justiça criminal internacional.

\section{Tribunal Penal Internacional na grande estratégia dos Estados Unidos}

Não é novidade que os Estados Unidos atuam de forma a interferir na agenda, no mandato e nos instrumentos dos fóruns internacionais de direitos humanos, e, ao mesmo tempo, rechaçam as recomendações ou decisões dessas instâncias. Essa postura pode ser interpretada como resultado da posição privilegiada que o país ocupa no sistema internacional, o que pressupõe autonomia decisória e, por esse motivo, uma atitude que busca isentar o país de compromissos internacionais que possam limitar seu campo de ação estratégica. Também é fruto de uma "autocompreensão política e cultural" da singularidade do país, com instituições superiores e o dever de promover os direitos humanos em seu território, "e também de fazer valer a responsabilidade de governantes e outros agentes por violações de direitos praticadas no seu território ou no exterior" (Maia, Koerner e Maciel, 2017).

Ambas as explicações ganham abrigo no campo das análises sobre a grande estratégia dos Estados Unidos, que, desde a Segunda Guerra, está fortemente vinculada à instalação e à promoção da ordem liberal internacional sob a liderança do país. A combinação das ideias liberais do wilsonianismo e do balanço de poder do realismo caracteriza as abordagens de inserção internacional do período (Nye Junior, 2019).

Mesmo com o fim da Guerra Fria, os presidentes Clinton, W. Bush e Obama alinhavaram suas estratégias 
no propósito de, sob o manto da liderança global, expandir a democracia e o livre mercado no mundo. Apesar das divergências sobre os meios para alcançar os objetivos, havia uma concordância sobre a solidez do esforço. O tema de direitos humanos e os instrumentos multilaterais que visam sua promoção e defesa vinculam-se, portanto, a um projeto de inserção do país que alia segurança e valores, presentes tanto nas administrações republicanas como democratas (Apodaca, 2006; Forsythe, 2000; Sikkink, 2004).

Essas abordagens são marcadas pelo apoio aos tribunais de exceção, ao mesmo tempo em que asseveram autonomia para liderar políticas, muitas vezes interventivas, de expansão das democracias. Por outro lado, em maior ou menor grau, todas hesitam em relação ao TPI. A razão está na própria estrutura do órgão: o tratado de Roma, seu documento constitutivo, criou um mecanismo permanente e independente do Conselho de Segurança da Organização das Nações Unidas (ONU), com jurisdição complementar às domésticas para os crimes de agressão, de guerra, contra a humanidade e de genocídio. Diferentemente dos tribunais de exceção e híbridos, o TPI pode iniciar investigações de crimes ocorridos e indiciar cidadãos de Estados não membros, conforme a sua legislação. Essa característica é potencial ameaça aos interesses dos Estados Unidos, especialmente em razão da forte atuação militar no mundo, assim como confere ao mecanismo uma característica de supranacionalidade que é de difícil aceitação, visto que concebem as próprias instituições domésticas como superiores e modelos para outras nações.

A face wilsoniana da grande estratégia internacionalista liberal dos três presidentes foi matizada pela abordagem multilateral em Clinton e Obama e pela combinação de políticas unilaterais 
com o chamado "multilateralismo ad hoc" de W. Bush. ${ }^{4}$ Nesse contexto, os tribunais de exceção se constituíram como meios para o alcance de objetivos de promoção dos valores norte-americanos. Já o TPI se tornou um instrumento indesejável, pelo menos na forma como se apresenta. Clinton e Obama privilegiaram uma abordagem diplomática com vistas a reformar o documento para isentar cidadãos dos Estados Unidos da jurisdição do TPI. Bush privilegiou uma política de combate ao mecanismo como forma de isentar os norte-americanos da jurisdição do órgão - política que sofreu ajustes no final do segundo mandato se aproximando das abordagens dos presidentes democratas (Maia, 2012).

Quanto à administração de Trump, as primeiras declarações dos funcionários de seu governo sobre o TPI eram consistentes com política de engajamento positivo de Obama. Como exemplo, destacam-se duas manifestações de diplomatas no Conselho de Segurança: a primeira, de congratulação à promotoria pelo trabalho na Líbia - proferida por Stephen Townley -, e a segunda, de apoio ao trabalho no caso do Sudão - proferida por Michele Sison (United States Mission to the United Nations, 2017a; 2017b). Segundo Taylor Ackerman, um associado da organização não governamental American Coalition for the International Criminal Court (AMICC), a abordagem inicial para o TPI poderia ser intencional, ou seja, uma decisão de permanecer com a política para o mecanismo, já que seria compatível com os objetivos do governo, mas também poderia significar que as instâncias estivessem ecoando declarações anteriores, na ausência de uma nova diretriz de Washington.

\footnotetext{
4 Krauthammer (2004, p. 12) esclarece que a influência neoconservadora na política de Bush pode ser vista em ações não necessariamente contrárias às ações multilaterais, mas pela preferência do multilateralismo ad hoc, ou seja, mediante coalizões internacionais que dispensam a atuação de organizações internacionais. No campo da justiça, são favoráveis a julgamentos internacionais desde que sejam aplicados aos povos "não civilizados".
} 
O documento que poderia solucionar essas dúvidas, o NSS do governo Trump, foi emitido em dezembro de 2017 com a promessa do presidente de colocar em primeiro lugar a segurança, os interesses e o bem-estar dos cidadãos estadunidenses. De forma distinta dos NSS dos governos Clinton, W. Bush e Obama, o relatório de Trump não fez qualquer menção aos instrumentos de justiça internacional, nem mesmo aos tribunais de exceção.

Contrariando aqueles que queriam permanecer otimistas sobre a possibilidade de um bom relacionamento entre a administração Trump e o Tribunal, a ascensão de John Bolton ao posto de conselheiro de Segurança Internacional minou essas esperanças. Assim que assumiu o cargo, acelerou um processo de desengajamento dos instrumentos internacionais de direitos humanos e, em 10 de setembro de 2018, anunciou retomada do boicote ao TPI (Bolton, 2018).

\section{O Tribunal Penal Internacional na grande estratégia do governo Trump}

Com efeito, os primeiros anos do governo Trump foram uma incógnita quanto à sua "grande estratégia" em curso. Alguns estudos (Dombrowski e Reich, 2017; Lissner e Zenko, 2017) afirmam que o governo simplesmente não tem uma grande estratégia. Para Lissner e Zenko (2017), as ações da administração são puramente reativas, sem uma lógica subjacente. Para Dombrowski e Reich (2017), os sinais confusos que o governo emite são resultado de uma abordagem que pretende mudanças significativas na estratégia dos Estados Unidos, mas que enfrenta obstáculos impostos pelas próprias instituições norte-americanas e embates entre os diferentes grupos que compõem a política.

A discussão também sustenta que a crença de alguns autores (Abrams, 2017; Kroenig, 2017) na continuidade da grande estratégia republicana em Trump é infundada. Autores como Ikenberry (2018), Nye Junior (2019) e Posen (2018) 
identificam uma estratégia em Trump marcada pela rejeição ao papel dos Estados Unidos como promotor da ordem internacional liberal e uma ruptura com as demais estratégias anteriores. Para Nye, o forte componente realista da grande estratégia de Trump é marcado por propostas nacionalistas, protecionistas e por uma mudança importante: a rejeição à democracia enquanto valor a ser propagado (Nye Junior, 2019, p. 67). Posen (2019) nomeia essa estratégia de "primazia sem propósito".

O Relatório de Estratégia de Segurança Nacional de 2017 foi dividido em quatro pilares: a proteção do povo, do território e do modo de vida americano; a promoção da prosperidade americana; a preservação da paz pela força; e o avanço da influência americana.

Em uma leitura do documento que buscou identificar pistas sobre a relação com os mecanismos de justiça internacional, identificou-se, no espaço dedicado ao avanço da influência americana, o objetivo de alcançar melhores resultados nos fóruns multilaterais. O meio para obter esse alcance é a reforma desses mecanismos, uma vez que, na visão da administração, as organizações internacionais servem de fórum para promover interesses de atores autoritários. ${ }^{5} \mathrm{Na}$ mesma seção do documento, esclarece que os Estados Unidos não cederão soberania aos organismos multilaterais "que reivindicam autoridade sobre os cidadãos americanos e estão em conflito com a estrutura constitucional" do país (The White House, 2017b, p. 40, tradução nossa). O compromisso com a responsabilização de perpetradores de genocídio e atrocidades em massa é citado, mas o

\footnotetext{
${ }^{5}$ Interessante que a instrumentalização de órgãos de direitos humanos pela potência foi e tem sido também a justificativa de governos violadores de direitos humanos para o não cumprimento de decisões e sentenças internacionais.
} 
meio para alcançar esse fim não é especificado ${ }^{6}$ (The White House, 2017b).

No espaço dedicado à busca da paz pela força, o documento afirma que os adversários devem ser persuadidos de que, se atacarem os Estados Unidos, não serão apenas punidos, mas derrotados. A tática para a dissuasão do inimigo é o convencimento de que eles não poderão alcançar seus objetivos por meio da força ou outras formas de agressão (The White House, 2017b).

Diante da acirrada disputa de interesses que normalmente está presente na criação do referido Relatório, a administração Trump logrou consenso em alguns tópicos, fornecendo uma orientação para a compreensão da coerência de políticas específicas. Um aspecto central do documento que traz implicações diretas para a forma como os temas de direitos humanos são incorporados na agenda multilateral é o reconhecimento de que os valores norte-americanos não podem ser impostos. No relatório consta: "Nós também somos realistas e entendemos que o American Way of Life não pode ser imposto a outros, nem é o resultado inevitável do progresso" (The White House, 2017b, p. 20, tradução nossa).

Assim, o que dava sentido às políticas de Clinton, W. Bush e Obama para os instrumentos de justiça penal internacional não faz mais parte do relatório publicado no período Trump, o que segue uma visão já declarada por ele no período eleitoral. Outro aspecto relevante para essa discussão é o ceticismo com relação à capacidade de

\footnotetext{
6 A palavra "direitos humanos" aparece uma única vez no NSS da administração Trump, vinculada à prioridade de apoiar a dignidade dos indivíduos. Segundo o Relatório, os Estados Unidos apoiam com ações e palavras os que vivem em regimes opressivos e que buscam a liberdade, a dignidade e o Estado de direito. Mas afirmam que os Estados Unidos não estão obrigados a oferecer as vantagens da liberdade e prosperidade americanas a regimes repressivos e violadores de direitos humanos. Poderão usar diplomacia, sanções e outros meios para isolar Estados e líderes que ameaçarem os interesses e cujas ações contrariarem os valores do país. Farão genocidas e perpetradores de crimes em massa prestarem contas de suas ações.
} 
instituições multilaterais de estabelecerem uma ordem favorável aos interesses dos Estados Unidos.

A partir de janeiro de 2017, é possível notar o início do processo de desengajamento dos Estados Unidos de instâncias multilaterais de cooperação, que têm como exemplos a ordem executiva com a previsão de cortes de financiamento para as organizações internacionais ${ }^{7}$ e as ações de retirada dos Estados Unidos do Trans-Pacific Partnership (TPP), do Acordo de Paris e da Organização das Nações Unidas para Educação e Cultura (Unesco).

Houve também forte deslegitimação de organizações internacionais de direitos humanos, com a ausência na audiência da Comissão Interamericana de Direitos Humanos em março de 2017, a qual trataria de denúncias referentes a ações do governo Trump (banimento e políticas de detenção de imigrantes, construção do muro na fronteira com o México e aprovação do Dakota Access Pipeline). ${ }^{8}$

Com a indicação de John Bolton para Conselheiro de Segurança Nacional, ${ }^{9}$ o processo de

\footnotetext{
7 A ordem executiva intitulada "Auditing and Reducing US Funding of International Organizations" pedia o corte de financiamento de organizações internacionais em $40 \%$, mas também pedia a suspenção de financiamento para organizações que aceitassem a participação da Palestina, promovessem o aborto, contornassem sanções ao Irã e Coreia do Norte. Solicitava também a criação de uma Comissão para a avaliação desses cortes que deveria observar os financiamentos de operações de paz, o Tribunal Penal Internacional e o Fundo de População das Nações Unidas que supervisiona programas de saúde materna e reprodutiva. Outra ordem executiva pedia uma revisão dos tratados internacionais, entre eles o acordo de Paris.
}

8 O caso Dakota Access Pipeline se refere às denúncias sobre impacto ambiental e desrespeito ao solo sagrado de comunidades indígenas gerados pela construção de um oleoduto de 1.186 quilômetros que vai de Bakken (no noroeste da Dakota do Norte) passando por Dakota do Sul, Iowa até Patoka, no Illinois.

${ }^{9} \mathrm{Na}$ ocasião da confirmação de Bolton como Conselheiro de Segurança Nacional, o The New York Times comentou que a substituição de HR McMaster, bem como a ascensão de Mike Pompeo como secretário de Estado com a saída de Rex Tillerson, significava uma equipe de política externa mais agressiva (Sanger, 2018). É conhecida a oposição de Bolton à participação dos Estados Unidos nessas instâncias. Como embaixador dos Estados Unidos na Organização das Nações Unidas durante o governo Bush, defendeu a saída dos Estados Unidos do Conselho de Direitos Humanos. Também como funcionário da administração atuou na defesa das medidas anti-TPI. 
desengajamento multilateral foi intensificado. Em junho de 2018, houve a retirada do país do Conselho de Direitos Humanos das Nações Unidas, em meio às críticas dirigidas ao endurecimento da política anti-imigração. Na ocasião, Matheus Hernandez (2018), estudioso sobre a relação entre o Conselho e os Estados Unidos, previu o que ele chamou de outros "cartões vermelhos" para as demais instituições internacionais.

Em meio às críticas, novos desligamentos de instituições foram registrados. O secretário de Estado e o conselheiro de Segurança Nacional, respectivamente, declararam a saída de dois tratados internacionais que conferem à Corte Internacional de Justiça a jurisdição sobre disputas concernentes à interpretação e suas aplicação; devido, na primeira situação, a uma apelação do Irã sobre sanções impostas pelos Estados Unidos e, na segunda, a uma denúncia da Palestina pela realocação da embaixada dos Estados Unidos para Jerusalém como violação do direito internacional. ${ }^{10}$

Bolton (apud Galbraith, 2019) buscou justificar as ações, declarando-as consistentes com as de administrações anteriores. Citou a decisão de Ronald Reagan, em 1980, de anular a aceitação da jurisdição compulsória da Corte Internacional de Justiça, e também a decisão de W. Bush, em 2005, de retirar os Estados Unidos do Protocolo Opcional de Viena sobre Relações Consulares, considerando que ele interferia na justiça criminal doméstica. ${ }^{11} \mathrm{O}$ argumento mantido é o da politização do uso desses mecanismos em retaliação aos Estados Unidos.

\footnotetext{
${ }^{10}$ A ênfase especial no caráter de Jerusalém - o status legal da cidade - e resoluções anteriores do Conselho de Segurança que recusam os esforços de Israel para a mudança desse status foram os subsídios utilizados pela Palestina para levar a controvérsia à Corte Internacional de Justiça.

11 Sobre a relevância do caso na discussão do tema da pena de morte e imigração, vale conferir Barreira e Belangero (2017).
} 
Assim, a metáfora do cartão vermelho poderia servir também para o TPI, se este for considerado como um mecanismo "que está em campo" e que "joga contra" os objetivos de um jogo em que os Estados Unidos são o juiz. No entanto as manifestações sobre o Tribunal não significam simplesmente mandar o jogador para o banco de reservas. Significam que ele, como empecilho para a fluidez do jogo (portanto antagonista do juiz), deve ser aniquilado ou, no mínimo, neutralizado.

Dito isso, a marcante manifestação de Bolton em 10 de setembro de 2018 condiz com o esperado, retomando o discurso de oposição ao TPI do primeiro mandato de W. Bush, ressuscitando as medidas anti-TPI e anunciando novas formas de retaliação, agora dirigidas não somente à organização, mas aos funcionários do Tribunal. ${ }^{12} \mathrm{~A}$ mensagem, conforme as próprias palavras do conselheiro, foi clara e inequívoca: ${ }^{13}$ "Nós não vamos apoiar o TPI. Nós não vamos nos juntar ao TPI. Nós deixaremos o TPI morrer sozinho. Afinal, para todos os efeitos, o TPI já está morto para nós" (Bolton, 2018, tradução nossa).

Seis aspectos foram apontados para sustentar a revitalização da política de combate ao Tribunal: (a) a jurisdição sobre oficiais norte-americanos que ameaça os interesses de

\footnotetext{
12 As medidas dirigidas ao TPI anunciadas pela administração Trump podem ser assim resumidas: (a) a ampliação do número de acordos bilaterais de não entrega; (b) medidas de retaliação contra o pessoal do TPI (proibição de entrada nos Estados Unidos, aplicação de sanções contra seus bens no sistema financeiro americano, início de processos no sistema criminal dos Estados Unidos) e contra empresas ou Estados que auxiliem investigações no Tribunal sobre norte-americanos; (c) monitoramento dos países que cooperarem com as investigações do TPI e levar isso em consideração quando se avaliar a política de assistência externa, assistência militar e compartilhamento de inteligência; (d) medidas no Conselho de Segurança da ONU para restringir os amplos poderes do tribunal, incluindo assegurar que o TPI não exerça jurisdição sobre os norte-americanos de nacionais de países aliados que não tenham ratificado o Estatuto de Roma.

13 Bolton claramente põe em prática sua proposta apresentada em julho de 1998 na audiência no Comitê de Relações Exteriores do Senado, quando foi discutida a postura que a administração Clinton deveria adotar com relação à assinatura do Estatuto do TPI. Ele defendeu o que chamou de "três nãos" para o TPI: não ao apoio financeiro, não à colaboração e não à negociação para reformar o Estatuto.
} 
segurança nacional; (b) a definição dos crimes do TPI que estão em disputa; (c) os apoiadores do TPI interessados em intimidar os decisores dos Estados Unidos e de outras sociedades democráticas; (d) a falha do TPI no objetivo de dissuadir o cometimento de crimes; (e) a defesa da superioridade das instituições domésticas; e (f) as críticas de antigos apoiadores. ${ }^{14}$

Vale mencionar um esclarecimento feito pelo próprio Bolton:

Nós adotamos essa posição, não porque nos opomos à justiça para vítimas de atrocidades, mas porque nós acreditamos que os perpetradores de crimes devem enfrentar processos judiciais legítimos, eficazes e responsáveis em governos nacionais soberanos. (Bolton, 2018, tradução nossa)

Essa passagem, aparentemente sem relevância perante as seis preocupações centrais que dão suporte à política voltada ao TPI, sugeriu uma mudança na orientação da política dos Estados Unidos direcionada aos instrumentos de justiça internacional como um todo: a retirada de apoio aos tribunais de exceção e híbridos. Bolton foi claro ao dizer que o país aprova julgamentos, desde que sejam realizados por Estados soberanos, o que, segundo Jane Stromseth (2018), iria de encontro ao consenso forjado em duas décadas de administrações democratas e republicanas de apoio aos tribunais ad hoc e híbridos, em que promotores e juízes norte-americanos serviram.

As críticas não tardaram. Segundo Scheffer (2018), o double standard estabelecido no discurso de Bolton

\footnotetext{
14 É no mínimo curiosa a menção que Bolton faz sobre as ameaças de saída em massa de países africanos do TPI. Segundo ele, as críticas desses países se dirigem à percepção de que o Tribunal é um empreendimento neocolonial europeu para infringir os direitos soberanos.
} 
funcionará para regimes autoritários que ganharão força na resistência à responsabilização por crimes internacionais. Disse ainda que o discurso do Conselheiro de Segurança revela medo e fraqueza diante da organização. Bellinger (2018) chamou de infeliz o curso de ação adotado pela administração Trump para o TPI. Para ele, a saída ideal seria o uso da diplomacia, e não lançar um desafio público ao TPI. Essa percepção é compartilhada por Stromseth (2018), que acredita que seriam mais racionais e efetivas medidas como a ação da administração Obama, que gerenciou a proteção dos interesses dos Estados Unidos de forma efetiva na negociação em Kampala, assegurando que o crime de agressão não pode ser aplicado aos Estados não membros do TPI.

Em 15 de março de 2019, o secretário de Estado reforma a posição anteriormente apresentada ao declarar que os Estados Unidos continuarão direcionando ajuda externa para o fortalecimento de sistemas de justiça domésticos de nações estrangeiras como forma de combate à impunidade e que também apoiam mecanismos jurídicos híbridos internacionais, quando operarem de maneira eficaz e consistente com o interesse do país. Citou como exemplos os tribunais de Ruanda e para a ex-Iugoslávia, e os esforços internacionais de coleta de evidências na Síria e Birmânia. Contudo, na mesma data, reiterou a abordagem de combate ao TPI, anunciando a primeira medida de retaliação aos funcionários da organização: a restrição de vistos para indivíduos diretamente responsáveis por investigações que envolvam pessoal norte-americano e também que envolvam investigações contra israelenses.

Nas palavras do secretário de Estado, a política para o TPI está inserida na "intenção da administração Trump de reformar as instituições internacionais, reorientando-as para as suas missões principais" (US Department of 
Defense, 2019). ${ }^{15}$ Argumentou que as investigações do TPI no Afeganistão confirmaram o receio já presente na administração Bush do uso político do TPI. ${ }^{16}$ Por fim, alertaram que não é tarde para que o TPI mude seu curso de ação (US Department of Defense, 2019).

\section{Considerações finais}

Diferentemente dos NSS de Clinton, W. Bush e Obama, em que os direitos humanos e instrumentos de justiça internacional vinculam-se à estratégia de promoção da justiça como valor e à expansão das democracias o documento produzido na administração Trump deixa claro que valores não podem ser impostos. Além disso, as ações de desengajamento de instituições multilaterais de direitos humanos evidenciam o ceticismo com relação ao papel desses mecanismos como promotores de uma ordem favorável aos interesses dos Estados Unidos. De toda forma, esses mecanismos também perdem sua função em uma estratégia que tem no unilateralismo seu principal curso de ação.

Soma-se a isso o descrédito atribuído às instituições multilaterais de direitos humanos que, nos discursos oficiais, são

\footnotetext{
15 Essa afirmação não condiz com a política dos três nãos presentes no discurso de Bolton. A afirmação que o TPI já está morto para os Estados Unidos não indica qualquer intenção de negociação para reforma do mesmo. Cf. nota 12.

16 Vale esclarecer que Trump, no período eleitoral, afirmou que retiraria as tropas do Afeganistão. No início do seu mandato, o presidente Trump muda de ideia, inclusive torna mais agressiva a abordagem para o Afeganistão com o envio de mais tropas. Além disso, buscou um maior engajamento da Organização do Tratado do Atlântico Norte (Otan) e buscou negociar com o Taliban. Segundo Mehta e Copp (2017), a mudança de estratégia para o Afeganistão trouxe uma abordagem mais agressiva, a ampliação do número de tropas e novas regras de engajamento das tropas que ampliaram a exposição de civis aos efeitos colaterais dos enfrentamentos e menos responsabilização dos soldados, que foram autorizados a abrir fogo sem respeitar certa proximidade dos alvos dos ataques. Nesse contexto, em novembro de 2017, a promotora do TPI anunciou o início de investigações formais de supostos crimes cometidos no Afeganistão, tanto por membros do Taliban como pelas forças armadas norte-americanas (a investigação preliminar que já ocorria desde 2016 evidenciava as práticas de tortura geridas por agências de inteligência dos Estados Unidos).
} 
criticadas como instâncias politizadas com vistas a retaliar os Estados Unidos.

A omissão no NSS de Trump dos tribunais de exceção e híbridos (instâncias que aparecem em todos os relatórios dos governos do pós-Guerra Fria como instrumentos que servem aos interesses norte-americanos) revela que eles não figuram mais como meios ou instrumentos no alcance de objetivos estratégicos dos Estados Unidos. De maneira diversa à política de Bush, que de antemão considerava esses tribunais como artifício para alcançar os interesses do país, a retórica do secretário de Estado de Trump deixa clara a abordagem ad hoc para os tribunais.

A retomada da hostilidade com relação ao TPI mostra uma dimensão do consenso entre as quatro administrações: que o mecanismo, da forma como está desenhado, não responde aos interesses dos Estados Unidos. Diferentemente de Clinton e Obama, que buscaram conviver com o Tribunal e negociar sua reforma para proteger seus nacionais da jurisdição, W. Bush adotou, especialmente no primeiro mandato, uma estratégia de combate ao TPI registrada em seu NSS (The White House, 2002). Os efeitos colaterais das medidas levaram a administração a abrandar a política. Em 2006 não aparece qualquer menção ao TPI no relatório. A administração Trump também não menciona o TPI em seu NSS (The White House, 2017b), além disso, nos primeiros meses de mandato não altera as diretrizes do governo anterior com relação ao TPI (conforme pudemos observar nas manifestações de apoio às investigações da promotora).

No entanto essa posição é drasticamente alterada. Trump ressuscita a política de forte oposição ao mecanismo e dá a ela uma nova tática: a de sanção aos funcionários do órgão. A ameaça ocorre especialmente em face do anúncio da promotora do TPI do início de investigações formais sobre crimes de guerra no Afeganistão e seus desdobramentos. No contexto das ações de um governo que busca alcançar a 
paz pela força e adota ações diplomáticas de negociar com inimigos - inclusive com o Taliban -, de fato as investigações do Tribunal aparecem como empecilhos aos meios empreendidos pelos Estados Unidos no alcance dos seus interesses.

A ascensão de Bolton ao posto de Conselheiro de Segurança Nacional também contribuiu para a postura agressiva com relação ao mecanismo. Desde a negociação do TPI, Bolton tem se mostrado um forte opositor do mecanismo. Para além das questões que envolvem a atuação militar dos Estados Unidos no mundo, ele defende que o Tribunal contraria os preceitos básicos consagrados na Constituição do país.

\section{Marrielle Maia}

é doutora em Política Internacional pelo IFCH/Unicamp, mestra e bacharela em Relações Internacionais pela Universidade de Brasília (UnB), especialista em Direitos Humanos pelo programa da parceria da ESMPDFT, UnB e University of Essex. É professora da graduação e pós-graduação em Relações Internacionais no IERIUFU, coordenadora do Núcleo de Pesquisas e Estudos em Direitos Humanos (NUPEDH/IERIUFU). É pesquisadora do INCT-Ineu e Ceipoc/Unicamp.

\section{Taynara Dias}

é mestranda e bacharela em Relações Internacionais pelo Programa de Pós-Graduação em Relações Internacionais da Universidade Federal de Uberlândia. É pesquisadora do Núcleo de Pesquisas e Estudos em Direitos Humanos (NUPEDH/IERIUFU) e também do Instituto Nacional de Ciência e Tecnologia para Estudos sobre os Estados Unidos (INCT-INEU). 


\section{Bibliografia}

ABRAMS, Elliott. 2017. Trump the traditionalist: a surprisingly standard foreign policy. Foreign Affairs, v. 96, pp. 10-16.

APODACA, Clair. 2006. Understanding U.S. Human Rights Policy:

A paradoxical legacy. New York: Routledge.

BARREIRA, Karen Sakalauska; BELANGERO, Juliana. 2017.

A mobilização do direito internacional dos direitos humanos e o Judiciário norte-americano: uma análise a partir do caso Medellín. In: MAIA, Marrielle; KOERNER, Andrei; MACIEL, Débora Alves. Os Estados Unidos e a Comissão Interamericana de Direitos Humanos: denúncias, interações, mobilizações. Brasília, DF: Funag. pp. 167-204.

BELLINGER, John. 2018. The Trump administration throws down the Gauntlet to the OCC. The court should decline the challenge. Lawfare. Disponível em: http:/ / bit.ly/2PdfodO. Acesso em: 15 set. 2018.

BOLTON, John. 2018. Full text of John Bolton's speech to the Federalist Society. Al Jazeera News. Disponível em: http:/ / bit.ly/2PdEtVY.

Acesso em: 22 out. 2019.

DOMBROWSKI, Peter; REICH, Simon. 2017. Does Donald Trump have a grand strategy? International Affairs, v. 93, n. 5, pp. 1013-1037.

DORFF, R. H. 2001. A Primer in Strategy Development. In: CERAMI, Joseph; HOLCOM JUNIOR, James (eds.). U.S. Army War College Guide to Strategy. Carlisle: US Army War College. pp. 11-17.

FORSYTHE, David P. 2000. Human Rights in International Relations.

Cambridge: Carmbridge University Press.

GALBRAITH, Jean. 2019. Contemporary practice of the United States relating to International Law (113:1 Am J Int'1 L). Faculty Scholarship at Penn Law, v. 2037, n. 1, pp. 131-182. Disponível em: http://bit.ly/2MCVNln. Acesso em: 2 mar. 2019.

HERNANDEZ, Matheus de Carvalho. 2018. O cartão vermelho de Trump para o Conselho de Segurança da ONU. Estadão. Política. Disponível em: http://bit.ly/2N4C39f. Acesso em: 14 ago. 2018.

IKENBERRY, G. John. 2017. The plot against American foreign policy: can the liberal order survive. Foreign Affairs, v. 96, p. 2.

KRAUTHAMMER, Charles. 2004. Democratic realism: an American foreign policy for a unipolar world. Washington, DC: The AEI Press.

KROENIG, Matthew. 2017. The case for Trump's Foreign Policy: the right people, the right positions. Foreign Affairs, v. 96, p. 3.

LAYNE, Christopher. 1998. Rethinking American grand strategy hegemony or balance of power in the twenty-first century? World Policy Journal, v. 15, pp. 8-28. 
LISSNER, Rebecca; ZENKO, Micah. 2017. There is no Trump doctrine, and there will never be one. Foreign Policy. Disponível em: http://bit.ly/2PbVuzN. Acesso em: 14 ago. 2018.

MAIA, Marrielle. 2012. O Tribunal Penal Internacional na grande estratégia norte-americana (1990-2008). Brasília, DF: Funag.

MAIA, Marrielle. 2014. A grande estratégia dos Estados Unidos para o Tribunal Penal Internacional no pós-Guerra Fria. Politica $\mathcal{E}$ Sociedade, v. 12, n. 25, pp. 157-183.

MAIA, Marrielle; LEMOS, Gustavo Sales. 2017. Da negação da relação ao unliked marriage: o Pentágono na Relação entre os Estados Unidos e o TPI (1998-2016). Cadernos CEDEC, n. 122, pp. 5-25.

MAIA, Marrielle; KOERNER, Andrei; MACIEL, Debora A. 2017. Os Estados Unidos e a Comissão Interamericana de Direitos Humanos: denúncias, interações, mobilizações. Brasília, DF: Funag.

MEHTA, Aaron; COPP, Tara. 2017. Trump Afghanistan strategy calls for more troops, regional pressure. Military Times. Disponível em: http://bit.ly/33VSXh4. Acesso em: 21 ago. 2017.

NYE JUNIOR, Joseph. 2019. The rise and fall of American hegemony from Wilson to Trump. International Affairs, v. 95, n. 1, pp. 63-80.

POSEN, Barry. 2018. The rise of illiberal hegemony: Trump's surprising grand strategy. Foreign Affais, v. 97, p. 20.

SANGER, David. 2018. With Bolton, Trump creates a historically hard-line foreign policy team. The New York Times. Disponível em: https://nyti.ms/2N2j5Aa. Acesso em: 23 mar. 2018.

SCHEFFER, David. 2018. Ambass. David Scheffer on John Bolton's announcement of "ugly and dangerous" punitive actions against judges, prosecutors of Int'l Criminal Court. Just Security. Disponível em: http://bit.ly/2MHQhy6. Acesso em: 15 set. 2018.

SIKKINK, Kathrin. 2004. Mixed Signals: US Human Rights Policy and Latin America. New York: The Century Foundation.

SNIDER, Don M.; NAGL, John. 2001. The national security strategy. In: CERAMI, Joseph; HOLCOM JUNIOR, James (eds.). U.S. Army War College Guide to Strategy. Carlisle: US Army War College. pp. 127-142.

STROMSETH, Jane. 2018. Why Bolton's assault on the ICC is not in U.S. interests. Just Security. Disponível em: http://bit.ly/2BzzOWc.

Acesso em: 15 out. 2018.

THE WHITE HOUSE. 1995. A national security strategy of engagement and enlargement. Washington, DC: The White House.

THE WHITE HOUSE. 1996. A national security strategy of engagement and enlargement. Washington, DC: The White House. 
THE WHITE HOUSE. 1997. A national security strategy of engagement and enlargement. Washington, DC: The White House.

THE WHITE HOUSE. 1998. A national security strategy for a new century.

Washington, DC: The White House.

THE WHITE HOUSE. 1999. A national security strategy for a new century.

Washington, DC: The White House.

THE WHITE HOUSE. 2000. A national security strategy for a new century.

Washington, DC: The White House.

THE WHITE HOUSE. 2002. The national security strategy of United States of America. Washington, DC: The White House.

THE WHITE HOUSE. 2006. The national security strategy of United States of America. Washington, DC: The White House.

THE WHITE HOUSE. 2010. National Security Strategy. Washington, DC:

The White House.

THE WHITE HOUSE. 2017a. Daily Press Briefing by Press Secretary Sean

Spicer. Washington, DC: The White House. Disponível em:

http://bit.ly/2N8V1eO. Acesso em: 14 mar. 2019.

THE WHITE HOUSE. 2017b. National Security Strategy. Washington, DC:

The White House.

UNITED STATES MISSION TO THE UNITED NATIONS. 2017a.

Remarks at a UN Security Council Briefing on Sudan and the

International Criminal Court. United States Mission to the United Nations.

Disponível em: http://bit.ly/32FDCBj. Acesso em: 14 mar. 2019

[página atualmente indisponível].

UNITED STATES MISSION TO THE UNITED NATIONS. $2017 \mathrm{~b}$.

Remarks at a UN Security Council Briefing on the Situation in Libya.

United States Mission to the United Nations. Disponível em:

http://bit.ly/32Min0M. Acesso em: 14 mar. 2019

[página atualmente indisponível].

US DEPARTMENT OF DEFENSE. 2019. Remarks: Michael R.

Pompeo. Disponível em: https://www.state.gov/secretary/ remarks/2019/03/290394.htm. Acesso em: 18 mar. 2019 [página atualmente indisponível]. 